\title{
UNA NUEVA ESPECIE COSTARRICENSE DEL GÉNERO AMYRIS P. BROWNE (RUTACEAE)
}

\author{
JORGE GÓMEZ-LAURITO ${ }^{1}$ y QUÍRICO JIMÉNEZ ${ }^{2}$ \\ ${ }^{1}$ Escuela de Biología, Universidad de Costa Rica, Ciudad Universitaria 2060, San José, Costa Rica. \\ Investigador Asociado, Dept. of Botany, Field Museum of Natural History, Chicago, U. S. A. \\ ${ }^{2}$ Escuela de Ingeniería Forestal, Instituto Tecnológico de Costa Rica, Cartago, Costa Rica
}

\begin{abstract}
A new species of Amyris P. Browne (Rutaceae) with large opposite pinnate leaves is described from the central and southern Pacific region of Costa Rica.

Resumen. Una nueva especie de Amyris P. Browne (Rutaceae), con hojas muy grandes, opuestas y pinnadas, se describe de la región del Pacífico central y sur de Costa Rica.
\end{abstract}

Palabras Clave / Key words: Rutaceae, Amyris, Amyris magnifolia, Costa Rica

Amyris P. Browne (Rutaceae) es un género neotropical con unas 40 especies distribuidas en las Antillas y desde Florida y Texas en los Estados Unidos a través de América Central hasta Perú y Venezuela (Gereau 1991, Pool 1998, 2001). Este género consta de árboles o arbustos con hojas de $1 \mathrm{a}$ 11 foliolos, alternas u opuestas, flores perfectas, pequeñas y actinomorfas con 3-5 pétalos, 6-10 estambres libres y frutos drupáceos con una semilla. Usualmente son plantas muy aromáticas y algunas especies se han usado por su madera y como fuente de incienso y aceite (Mabberly 1997). Cuatro especies se han encontrado hasta ahora en Costa Rica y una quinta especie del Pacífico central y sur, con grandes hojas paripinnadas opuestas, se describe a continuación.

Amyris magnifolia Gómez-Laur. \& Q. Jiménez, sp. nova

TIPO: Costa Rica. Puntarenas. Osa. Reserva Forestal Golfo Dulce. Rancho Quemado. Fila al oeste de Tierra de Conservación, camino a Cerro Brujo, $200 \mathrm{~m}$ de elev. $08^{\circ} 46^{\prime} 20^{\prime \prime} \mathrm{N}, 8^{\circ} 22^{\prime} 40^{\prime \prime} \mathrm{O}, 15$ nov. 1993 (flores y frutos). R. Aguilar \& B. Hammel 2620 (holotipo INB, isotipos MO, NY, USJ).

FIG. 1

Species foliis pinnatis magnis $26-51 \mathrm{~cm}$ longis, foliolis $23-47 \mathrm{~cm}$ longis, 9,5-17 cm latis, a congeneribus diversa.

Arbustos 2-4 m de altura hasta árboles de $8 \mathrm{~m}$ de altura y $10 \mathrm{~cm}$ de DAP; las ramitas teretes a subcuadrangulares con muchas lenticelas y glándulas punteadas, glabras; las hojas paripinnadas opuestas; los pecíolos teretes a subcuadrados, $13-21 \mathrm{~cm}$ de largo, 3-5 mm de ancho, glabros, amarillo-verdosos, pardo oscuro a negruzcos en el punto de inserción con la rama. Raquis terete a subcuadrangular, $13-30 \mathrm{~cm}$ de largo, 3-4 mm de ancho, amarillo-verdoso. Peciólulos teretes, $15-19 \mathrm{~mm}$ de largo, pardo oscuros a negruzcos. Foliolos 3-4 pares por hoja, opuestos, verde opacos en el envés, los basales más pequeños hasta 12 $\mathrm{cm}$ de largo, 7,5 cm de ancho, los centrales y terminales muy grandes, 23-47 cm de largo, 9,5-17 cm de ancho, ovados, agudos a acuminados, glabros en haz y envés, el margen entero, la base cuneada, verde opacos por el envés. Inflorescencia de varias panículas en las axilas de las hojas superiores, $15-34 \mathrm{~cm}$ de largo, 5-15 cm de ancho, glabras, glanduloso punteadas. Flores 2-2,3 mm de largo, glomeruladas; pedicelos ca. $1 \mathrm{~mm}$ de largo, con pelos cortos esparcidos; bracteolas ca. $0,5 \mathrm{~mm}$ de largo, ovadas a anchamente ovadas, pilosas apicalmente; sépalos 4, glanduloso punteados, el margen apicalmente piloso; pétalos 3, ovados a oblongos, blancos, glanduloso punteados, el margen eroso; estambres 6 en 2 series, 3 cortos y 3 largos, los cortos con filamentos de ca. $0,5 \mathrm{~mm}$ de largo, los largos con filamentos de ca. 1 $\mathrm{mm}$ de largo, los filamentos ligeramente comprimidos, amarillos, las anteras ca. $0,5 \mathrm{~mm}$, suborbiculares, bitecas, basifijas, dehiscentes lateralmente; ovario angostamente oblongo, glanduloso punteado, sobre 


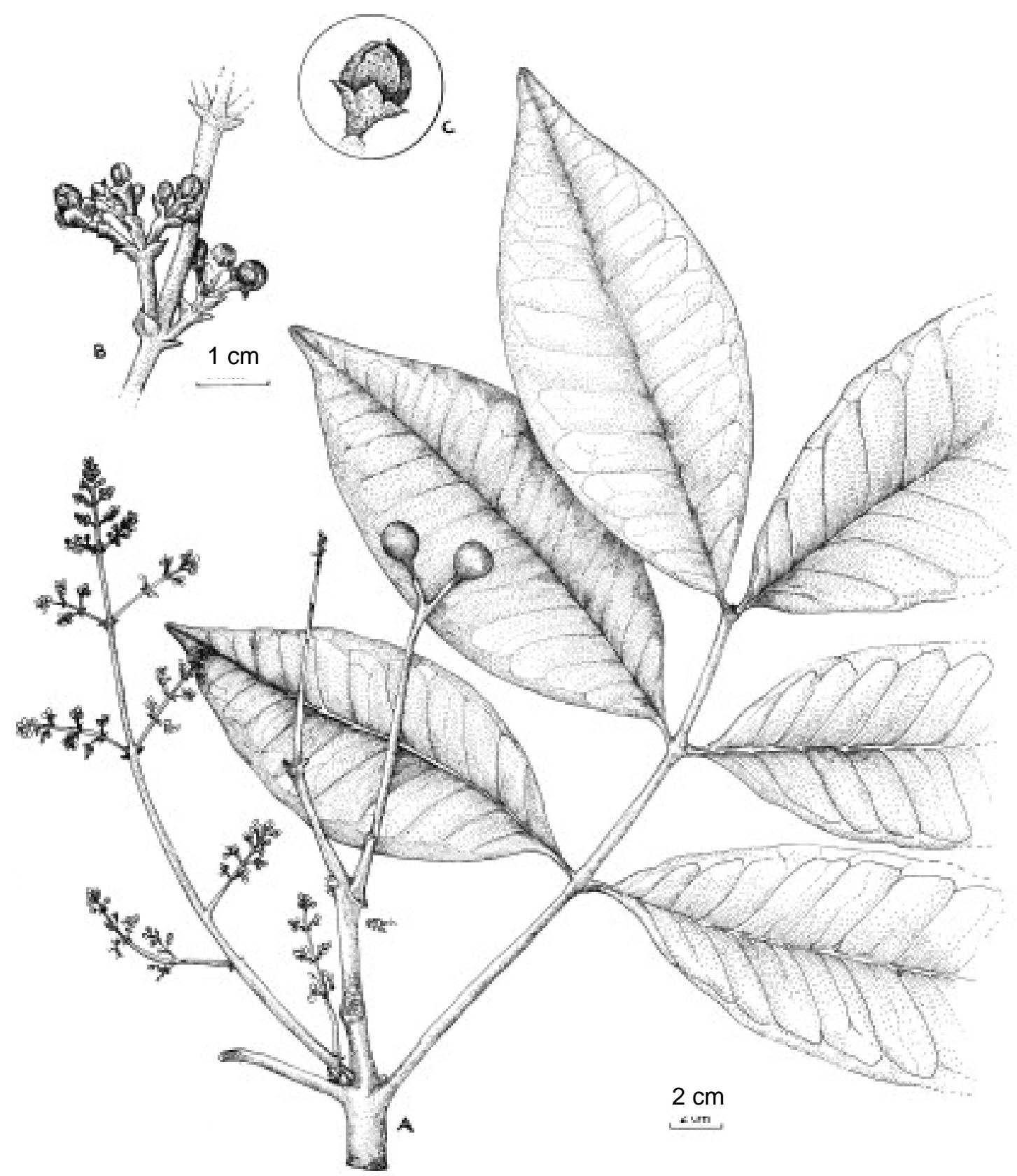

Fig. 1. Amyris magnifolia Gómez-Laur. \& Q. Jiménez. A - Hábito. B - Detalle de inflorescencia. C - Botón floral. Testigo: R. Aguilar \& B. Hammel 2620 (tipo).

un ginóforo de ca. $0,5 \mathrm{~mm}$, estigma capitado, disco anular presente. Frutos globosos, 10-12 mm de diámetro, verdes a blanquecinos, glanduloso punteados, aromáticos, con una sola semilla; pedúnculos 8 $10 \mathrm{~mm}$ de largo, teretes, glabros.
Paratipos: Costa Rica; Puntarenas. Reserva Biológica Carara. Edge of park near Río del Sur, foothills of Montañas de Jamaica, 9 ${ }^{\circ} 45^{\prime} \mathrm{N}, 84^{\circ} 32^{\prime} \mathrm{O}$, 150-400 m, 3 de abril 1993 (estéril), A. Gentry et al. 79349 (INB, MO). Osa. Reserva Forestal Golfo 
Dulce. Península de Osa. Los Mogos. Bahía Chal. Entrada Chocuaco, 846'20'N, 83²2'40”O, 200 m, 23 de agosto 1994 (estéril), R. Aguilar et al. 3579 (INB, CR, MO, USJ). Osa. Reserva Forestal Golfo Dulce, Osa Península, Rancho Quemado, ca. 15 km W of Rincón; in bottom of $\mathrm{S}$ end of Quebrada

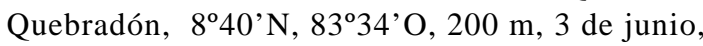
1988 (flores), B. Hammel et al. 16989 (INB). Golfito,

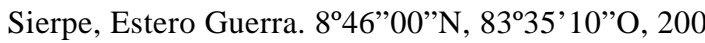
m, 6 de junio 1995 (flores), A. Estrada 425 (INB, CR, USJ). Golfito. Refugio Nacional de Vida Silvestre Golfito. Valle de Coto Colorado. Sendero natural siguiendo la fila, $3 \mathrm{~km}$ al norte del aeropuerto, 8'40'25”N, 83¹1'20”'O, $200 \mathrm{~m}, 27$ de enero 1992 (frutos), C. Formoso et al. 8 (CR, INB, MO, USJ). Golfito, Refugio Nacional de Vida Silvestre Golfito. Camino entre Golfito y La Gamba. Sendero a Cerro

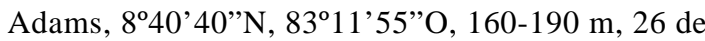
octubre 2002 (frutos), J. Gómez-Laurito et al. 13910 (USJ). Golfito. P. N. Corcovado. Valle de Coto Colorado. Punta Estrella y Punta Bejuco, $8^{\circ} 46^{\prime} 00^{\prime} \mathrm{N}$, $83^{\circ} 15^{\prime} 00$ ”'O, $100 \mathrm{~m}, 8$ de noviembre 1993 (frutos), Fco. Quesada \& M. Segura 810 (INB).

Esta especie ha sido confundida a través de los años con Amyris brenesii Standl., incluyendo A. costaricensis Standl. (Gómez-Laurito 1986). Sin embargo, A. brenesii, que también presenta pecíolos largos y foliolos grandes, es una especie con hojas trifolioladas y frutos elipsoides de 18-20 mm de largo y 13-15 mm de ancho, verdes a morados. Esta especie se distribuye principalmente en la región de San Ramón, estribaciones de las Cordilleras de Tilarán y Guanacaste y vertiente Caribe, de 20 a $1800 \mathrm{~m}$ de elevación. En zonas Subtropical, tropical, muy húmeda con 1-2 meses secos hasta Tropical, tropical, muy húmeda sin meses secos, de acuerdo al sistema de clasificación en Unidades Bióticas de Costa Rica de
Herrera \& Gómez (1993). Por otra parte, A. magnifo lia se reconoce fácilmente por sus grandes hojas paripinnadas opuestas con 3-4 pares de foliolos (de ahí el epíteto) y frutos globosos de 10-12 mm de diámetro, de verdes a blancos. Aparentemente alcanza su límite norte de distribución en la Reserva Biológica Carara, en el Pacífico central, donde se conoce de una sola recolecta estéril (Gentry et al. 79349). Es mucho más común en el Pacífico sur, en la Reserva Forestal Golfo Dulce (Península de Osa) y en el Refugio de Vida Silvestre de Golfito, provincia de Puntarenas, de 160 a 400 m de elevación. De acuerdo al sistema de clasificación de Herrera \& Gómez (loc. cit.), en regiones Tropical, tropical húmeda, con 3-4 meses secos, a Tropical, tropical muy húmeda sin meses secos.

Agradecimientos. A los estudiantes del curso de Botánica Forestal 2002, de la Escuela de Biología de la Universidad de Costa Rica, por su ayuda e interés, y a Carmen Marín por la excelente ilustración.

\section{LiterATURA CiTADA}

Gereau, R. E. 1991. El género Amyris (Rutaceae) en América del Sur, con dos especies nuevas de la Amazonia occidental. Candollea 46: 227-235.

Gómez-Laurito, J. 1986. Una nota corta sobre Amyris (Rutaceae). Brenesia 25/26: 321.

Herrera, W. \& Gómez, L. D. 1993. Mapa de unidades bióticas de Costa Rica. Escala 1: 685.000. Instituto Geográfico de Costa Rica.

Mabberly, D. J. 1997. The plant-book. 2 ed. Cambridge University Press. p. 34.

Pool, A. 1998. Amyris oblanceolata (Rutaceae), a new species from Nicaragua. Novon 8: 61.

2001. Amyris P. Browne. In: W. D. Stevens, C. Ulloa, A. Pool, O. M. Montiel (eds.) Flora de Nicaragua. Angiospermas (Pandanaceae-Zygophyllaceae). Missouri Botanical Garden Press. p. 2289-2290. 